\title{
Correction to: endoplasmic reticulum stress may activate NLRP3 inflammasomes via TXNIP in preeclampsia
}

\author{
Yong Yang ${ }^{1,2} \cdot$ Jianxin $\mathrm{Li}^{1,2,3} \cdot$ Ting-Li Han $^{1,3} \cdot$ Xianbo Zhou ${ }^{1,3} \cdot$ Hongbo Qi $^{1,3,4} \cdot$ Philip N. Baker ${ }^{3,4} \cdot$ Wei Zhou $^{2}$. \\ Hua Zhang ${ }^{1,3}$
}

Published online: 7 December 2019

(C) Springer-Verlag GmbH Germany, part of Springer Nature 2019

\section{Correction to: Cell and Tissue Research (Published on- line: 22 October 2019)}

https://doi.org/10.1007/s00441-019-03104-9

The authors apologize that in our published paper entitled "Endoplasmic reticulum stress may activate NLRP3 inflammasomes via TXNIP in preeclampsia" Cell and Tissue Research (Published online: 22 October 2019); The authorship and affiliation have the following errors. 1) The first author also belongs to Department of Obstetrics and Gynecology, The First Affiliated Hospital of Chongqing
Medical University; 2) Department of Obstetrics and Gynecology, The First Affiliated Hospital of Chongqing Medical University, should be listed as first in the affiliation.

The authors would like to regret any inconvenience caused by these errors.

For this reason, in our article we correct the following typographic errors in the text:

Publisher's note Springer Nature remains neutral with regard to jurisdictional claims in published maps and institutional affiliations.

Yong Yang and Jianxin Li contributed equally to this work.

The online version of the original article can be found at https://doi.org/ 10.1007/s00441-019-03104-9

Wei Zhou

dr.zhouwei@163.com

Hua Zhang

zh2844@gmail.com

1 Department of Obstetrics and Gynecology, The First Affiliated Hospital of Chongqing Medical University, No. 1 Youyi Road, Yuzhong District, Chongqing 400016, People's Republic of China

2 Department of Obstetrics, Chongqing Health Center For Women And Children, No. 120 Longshan Road, Yubei District, Chongqing 400021, People's Republic of China

3 Canada - China -New Zealand Joint Laboratory of Maternal and Fetal Medicine, Chongqing Medical University, No. 1 Yixueyuan Road, Yuzhong District, Chongqing 400016, People's Republic of China 